Looking to the

future, we may

yet see more

psychiatric

disorders

emerging as

a result of the

tsunami. available. This situation increases the suffering of the affected people and could mean fewer people with psychiatric problems present to the psychiatric service, as they are preoccupied with the day-to-day practical issues of re-establishing their homes and livelihoods.

Since the tsunami, some services (particularly community-based programmes) have been diverted to the tsunami-affected areas, and away from areas which have a high level of psychosocial need as a result of other factors, including poverty and conflict.

Looking to the future, we may yet see more psychiatric disorders emerging as a result of the tsunami, causing increased demand on already overstretched services, but the needs of those affected by the tsunami must be balanced and integrated with those of the rest of the population. The past year has seen unprecedented attention given to mental health by the Sri Lankan government, media and public. We hope this will provide an opportunity for Sri Lanka to reinforce and restructure mental health services for the benefit of the whole population.

\section{References}

Government of Sri Lanka (2005) Tsunami Disaster Figures as of 5th April 2005. Emergency Operation Room of the National Disaster Management Centre. Colombo: Ministry of Women's Empowerment and Social Welfare, Government of Sri Lanka.

Rose, S., Bisson, J. \& Wessely, S. (2002) Psychological debriefing for preventing post traumatic stress disorder (PTSD). Cochrane Database of Systematic Reviews, issue 2. Oxford: Update Software.

Saraceno, B. \& Minas, H. (2005) Mental Health Situation in Aceh. Geneva: WHO. Available at http://www.who.int/mental_health/ resources/Summary\%20Indonesia\%20Strategic\%20plan\%20 revised\%2027\%20Jan.pdf. Last accessed 20 April 2006.

Somasundaram, D. J., Yoganathan, S. \& Ganesvaran, T. (1988) Schizophrenia in Sri Lankan Tamils - a descriptive study. Ceylon Medical Journal, 38, I31-135.

World Health Organization (2003) Mental Health in Emergencies. Geneva: WHO.

World Health Organization (2004) Situational Reports on South-East Asia Earthquake and Tsunami. Available at http://w3.whosea. org/en/Section23/Section I 108/Section 1835_8139.htm. Last accessed 20 April 2006.

\title{
Different disasters, different needs
}

\section{Diyanath Samarasinghe}

Professor of Psychiatry, Faculty of Medicine, Kynsey Road, Colombo 8, Sri Lanka, email dsamara@vinet.lk

\section{With the tsunami \\ ... numerous \\ families lost \\ more than one \\ member. Indeed,}

in some instances,

not altogether

rare, just a single

member survived.

The needs of such

special survivors

are not addressed

adequately in the

usual responses to

disasters.

$$
\text { Ditem }
$$

ifferent kinds of disaster create dissimilar conditions for survivors, and the specific realities associated with each must guide our helping responses. This in no way negates the importance of having general principles to follow in responding to major disasters (Sphere Project, 2004; van Ommeren et al, 2005).

For instance, many of the families who lost one or more members in the tsunami that hit Sri Lanka in December 2004 also lost their homes, the rest of the community infrastructure and virtually all their belongings, but they lived alongside others similarly affected. Their experiences are of a different kind altogether from, for example, those who lost loved ones in the terrorist attacks in the United States on II September 200I - many of whom were geographically distant and for whom the physical infrastructure was mostly intact (Roxane et al, 2002; Simeon et al, 2003). Reactions against the presumed perpetrator, too, are of contrasting kinds in the two examples. Extreme anger and hostility are commonplace in disasters engineered by humans but virtually impermissible when the disaster is classed as an 'act of God'. These and other factors lead to major differences in what happens, and what we need to do, after any particular disaster.
I set out below some developments following the tsunami-related havoc in Sri Lanka which point to specific needs associated with disasters of this kind.

\section{Direct destruction affected whole families and communities}

Some disasters claim individual victims from any one family or social network. An example would be a terrorist bomb blast on a tube train, as happened in London in July 2005. Each bereaved family then usually has to respond to the loss of a single relative. With the tsunami, in contrast, numerous families lost more than one member. Indeed, in some instances, not altogether rare, just a single member survived. The needs of such special survivors are not addressed adequately in the usual responses to disasters. Their psychological needs are generally a later consideration in our formal planned responses.

There is perhaps a need to question the widespread acceptance of the benefits of medications and psychological intervention to facilitate emotional ventilation and cognitive adjustment among those affected by severe trauma (de Vries, 1998; Pupavac, 
2001 ; International Federation of Red Cross and Red Crescent Societies, 2001; Davidson, 2002; Rose et al, 2002; Alexander, 2005). The emotional support required urgently by the single survivor of a family battered by the tsunami was not at all of this kind. This person mostly needed just human contact. In massive destruction that wipes away 'natural' helpers, others have to step in. Our guidelines must emphasise that, in the wake of huge destruction, there will be isolated survivors who need urgent psychological help. The urgent help required, though, is simply to have a consistent and caring human being simply 'to be there', to hold or hug. This is rather more basic than what is called 'psychological first aid' (Sphere Project, 2004). Normal human contact is the most important psychological support - and this fact becomes evident only when its natural providers have all been wiped out.

The best longer-term path for the isolated survivor is not very clear either. Our tested strategies for helping people adjust and resume their previous lives, having come to terms with the loss, need not be the exclusive model on which to base interventions. Some victims may have benefited from being given room to consider starting altogether new lives by making this option part of the overt agenda and by creating the means of facilitating it. Several children had the opportunity to embark on entirely new lives, although through processes not within their control, while adults had to sit tight and adjust. The perception that starting anew reflects an unhealthy escape from proper grieving probably contributes to this avenue not being encouraged for adults.

\section{Wide scale and range of destruction}

The destruction of natural sources of help and comfort was the major impediment to a rapid and smooth transition into a recovery mode. Absence of family members was an obvious impediment to recovery. However, the absence of key staff and facilities also hampered helping responses. The local family health worker, too, may have, for example, suffered the loss of a family member or home. When plans are formulated to utilise staff in the affected areas, it is worth remembering that some of them may be unavailable or not in a fit state to participate in relief efforts.

Normal facilities, which are essential for the delivery of relief and other helping services, also form a basis for psychological recovery. School education was rapidly restored after the tsunami, often in alternative locations. This was a strong symbol of a return of normality - especially for the displaced still living in makeshift camps. There was, however, a delay in the return of other routines that could have implied a return to normality, such as going out to work and doing household tasks such as cooking and cleaning. Getting their children off to school was, for quite some time, the only regular meaningful function for many families - especially for those displaced and living in camps. Creating space and opportunities for as many normal routines as possible is an important ingredient in community and family adjustment.

\section{Understanding psychological needs and adjustment}

A woman who lost a child in the tsunami may often have had the survival of a remaining child, and of herself, to contend with immediately. The struggle to keep a surviving child alive probably serves to sweep away, temporarily, the classical reactions of numbness, denial, anger and even depression. What are swept away for the moment may return, to haunt, when conditions permit. On the other hand, they may not resurface at all.

Some of us may not want to believe that grief can somehow be bypassed, preferring instead the notion that these allegedly suppressed emotions must at some later stage be exorcised for complete comfort to reign. We try to allow, and perhaps even encourage, victims to ventilate and work through unhealthily suppressed emotions. How much of this need is that of the therapist or helper, as opposed to that of the victim, deserves more study.

Those directly affected can contribute to our understanding of people's reactions to loss and trauma. One aspect of this is the extent to which our grief is modulated by unavoidable involvement with life. Ensuring food, shelter and protection for surviving children is too pressing a task to allow distraction by grief for a child who has just died. An extreme conclusion from this would be that grief as we know it is a luxury permitted only to those who have the time and energy to spare. However, less extreme conclusions are worth exploring for their potential implications. Grief in animals in the wild is remarkably short-lived. Instances of profound and lasting grief, on the other hand, are recorded in domesticated animals, especially dogs.

Another lesson is the assuaging impact of seeing massive suffering right beside one's own. It may not be particularly useful, in trying to console a troubled client at a clinic, to point out that others have undergone similar bad experiences, but it is quite another matter to see others' suffering at first hand. When people devastated by the tsunami were crowded together with others in a similar condition, it appeared to have somehow made things easier to process. Many group treatments work by helping people share and learn from others with similar experiences. In adjustment after the tsunami, this happened in real life. The lesson is that helping services should actively encourage, or at the least allow, communal healing to work - rather than restricting themselves to models based on individual client-centred work.

\section{Fear of recurrence}

Some of us may not want to

believe that grief can somehow be bypassed, preferring instead the notion that these allegedly suppressed emotions must at some later stage

be exorcised for complete comfort to reign.

A characteristic associated particularly with the tsunami type of disaster was the continuous fear that 
another wave was in the offing. Panic-driven fleeing from the coast happened several times, set off by local false alarms as well as news of further quakes in the sea off Sumatra. In a few instances the mass media, too, with newly found concern for minimising harm from approaching tsunamis, fanned fears without good reason. Everybody was keen to ensure that they could not be accused of negligently failing to raise the alarm.

A tsunami affords scope for adequate early warning, to give people time to move to safety. In such circumstances a single designated agency that gives authoritative information is a great asset. Needless instances of dreadful panic-stricken fleeing could have been forestalled had we anticipated this occurrence and set up the means for people to recognise the real from the mythical next giant wave.

especially need guidance on how they should deal with powerless victims of disaster.

In approaching displaced groups and communities, government and non-government agencies would do well to modify their helping strategy according to the situation at hand.

\section{Spontaneous $v$. organised helping responses}

The immediate reaction of most people in the rest of the country, on first hearing news of the tsunami, was to rush to help in whatever way they could. A few, though, did seek to loot, plunder and exploit the vulnerable. The spontaneous public response managed admirably to ensure the survival and comfort of the vast numbers who were distraught, dispossessed and at risk of death or serious harm. There were no reports of anybody dying or suffering injury, infection, or even serious hunger or thirst after the first few hours, although in a few places women or girls were molested in the first day or two. 'People action', including that of medical volunteers, overall did a splendid job of ensuring the safety and survival of thousands at high risk.

The authorities moved in after things became more settled. Spontaneous humanitarian responses would gradually have dwindled and there was a need for this more systematic provision of materials, facilities and services. Many of those who felt insecure began to feel safer, but some of those who were making good progress by themselves probably began to feel restricted. A necessary consequence of the formal systems taking over was the shift of power away from the citizen to the official.

Having control over one's circumstances is an essential element of well-being. Control, even over their day-to-day lives, is hard to generate among people who are bereft of virtually all possessions. Helpers must then try extra hard to optimise autonomy.

People who have been 'officials' all their lives may especially need guidance on how they should deal with powerless victims of disaster. Two sources of potential authoritarianism have to be addressed. One is the stance generally adopted by some officials towards members of the supplicant public, simply from habit. The other is the unavoidable inattention to individual needs and sensitivities by people charged with the pressing task of providing essentials for the many. Efforts to moderate such tendencies in oneself and others would not go amiss. A brief session or two, say, to discuss how to deal with 'disaster victims' may be useful.

Health professionals, particularly mental health professionals, should not just see their role as helpers of traumatised individuals but recognise also their public health duty.

\section{Order $v$. disorder}

The time of initial disorder was disastrous for some. Stories circulated of women being molested and people fighting over meagre supplies. The nastiest examples were reported from highly disorganised settings. There were at the same time reports of sublimely selfless responses.

Some groups of displaced persons managed quickly to secure a system and order for their group, based on need and fairness. Such groups fared much better than those in which individuals and families were left to their own devices in the struggle for survival. Communally imposed order was accompanied by autonomy, with people collectively taking control of their situation, long before outside authority became established. Suffering was greatly mitigated in such settings. External authority was, however, life-saving when it established order in settings where the 'law of the jungle' had operated.

In approaching displaced groups and communities, government and non-government agencies would do well to modify their helping strategy according to the situation at hand. In communities with a high degree of collective responsibility, fairness and order, outside helpers must facilitate rather than replace the nascent efforts within. In others, they must first strive to create the necessary community processes.

\section{Conclusion}

Victims of the tsunami had their specific profile of characteristics. These included the loss of most anchors and normal routines, exposure to the real threat of a repetition of the onslaught, being in groups that shared similar traumas, not having opportunities to grieve in the ongoing struggle for survival, and being robbed of autonomy. Each of these has a strong bearing on how people respond and what others need to do to optimise adjustment.

\section{Recommendations}

O Include, in general guidelines on responding to disasters, a paragraph or two on the special features of different classes of disaster, with suggested specific responses in each. Examples relevant to the tsunami have been discussed above.

o Consciously review the degree of autonomy available to those affected and ensure that all feasible 
means to increase it are sought and pursued. This requires taking authority away from government and non-government agencies outside the community and placing it, to the maximum feasible extent, in the hands of those allegedly being helped.

- Facilitate the meaningul participation of the entire displaced (or otherwise affected) community in mutual support and reconstruction efforts. Look out for people being excluded.

O Include appropriate mental health considerations in the relief effort from the immediate aftermath onwards. Hardly any of the relevant public health promotional measures require expertise in clientcentred psychological help.

O Review the applicability to populations collectively exposed to major disasters of models for understanding grieving that have been derived from those surviving in very different circumstances. Grief reactions seen in more ordinary circumstances are modified here by two peculiar influences. First is the desperate struggle, at the same time as loved ones are lost, to ensure survival of those still alive. The forced and unremitting exposure to many others similarly affected is the second.

Mental health professionals must contribute to decisions on what will be optimal with regard to each of these and to the delivery of what such an analysis yields. This will at times call for much patience and determination.

\section{References}

Alexander, D. A. (2005) Early mental health intervention after disasters. Advances in Psychiatric Treatment, II, 12-18.

Davidson, J. R. T. (2002) Surviving disaster: what comes after the trauma? British Journal of Psychiatry, I8I, 366-368.

de Vries, F. (1998) To make a drama out of trauma is fully justified. Lancet, 35 I, I579-1580.

International Federation of Red Cross and Red Crescent Societies (200 I) Psychological Support: Best Practices from Red Cross and Red Crescent Programmes. Geneva: International Federation of Red Cross and Red Crescent Societies.

Pupavac, V. (200I) Therapeutic governance: the politics of psychosocial intervention and trauma risk management. Disasters, 25 358-372.

Rose, S., Bisson, J. \& Wessely, S. (2002) Psychological debriefing for preventing post traumatic stress disorder (PTSD). Cochrane Database of Systematic Reviews, issue 2. Oxford: Update Software.

Roxane, C. H., Holman, E., Mclntosh, D., et al (2002) Nationwide longitudinal study of psychological responses to September II. JAMA, 288, I235-1244.

Simeon, D., Greenberg, B. A., Knutelska, M. P. H., et al (2003) Posttraumatic reactions associated with the World Trade Center disaster. American Journal of Psychiatry, 160, 1702-1705.

Sphere Project (2004) Sphere Handbook (revised edn). Geneva: Sphere Project. Available at http://www.sphereproject.org/ handbook/index.htm. Last accessed 20 April 2006.

van Ommeren, M., Saxena, S. \& Saraceno, B. (2005) Mental and social health during and after acute emergencies: emerging consensus? Bulletin of the World Health Organization, 83, 71-75.

\section{Psychiatry in the Republic of Belarus}

\section{Natallia Golubeva ${ }^{1}$, Kris Naudts², Ayana Gibbs ${ }^{3}$, Roman Evsegneev ${ }^{4}$ and Siarhei Holubeu ${ }^{5}$}

${ }^{1}$ Forensic Psychiatrist, Department of Forensic Psychiatry, State Medical Forensic Service, Minsk, Belarus, email doctor_golubeva@mail.ru

${ }^{2}$ Deputy Director, Forensic Psychiatry Teaching Unit, Department of Forensic Mental Health Science, Institute of Psychiatry, King's College London, UK

${ }^{3}$ Wellcome Clinical Research Fellow, Section of Cognitive Neuropsychiatry, Division of Psychological Medicine, Institute of Psychiatry, King's College London, UK

${ }^{4} \mathrm{Head}$, Department of Psychiatry, Belarusian Medical Academy for Postgraduate Training, Minsk, Belarus

${ }^{5}$ Forensic Psychiatrist, Department of Forensic Psychiatry, State Medical Forensic Service, Minsk, Belarus

he Republic of Belarus (ROB) covers 207600

$\mathrm{km}^{2}$ and has a population of about 10 million (Ministry of Statistics and Analysis, 2005). It was a member state of the former Soviet Union until it gained independence in 1991. Belarus is located between Poland, Lithuania and Latvia in the west, Russia in the east, and Ukraine in the south. Seventy-two per cent of the population live in an urban environment and $28 \%$ in rural areas. The average life span for men is 63 years and for women 75 years (Ministry of Public Health, 2005).

\section{Mental health policies and programmes}

Historically, psychiatry in the ROB has been strongly influenced by the classical Russian-German school of thought. This implied a biologically oriented approach and an emphasis on hospital in-patient treatment. Over the past 10 years there has been a dramatic shift in ideology, views, priorities, legislation and care models in psychiatry in several former Soviet republics. Many of these countries have welcomed modern
The country profiles section of International Psychiatry aims to inform readers of mental health experiences and

experiments

from around

the world. We welcome potential contributors.

Please contact Shekhar Saxena (email saxenas@ who.int). 